\title{
Üniversite Öğrencilerinin Yaşamda Anlam ve Yaşam Amaçları Arasındaki İlişki
}

\author{
The Relationship between Meaning in Life and the Purpose of Life \\ for University Students
}

\section{Nur DEMİRBAŞ ÇELİK*}

Öz: Bu araştırmanın amacı, üniversite öğrencilerinin yaşamda anlam düzeyleri ile yaşam amacı düzeyleri arasındaki ilişkinin test edilmesidir. Ayrıca öğrencilerin cinsiyetinin yaşamda anlam, yaşamda anlam arayışı ve yaşam amacının üzerindeki etkisi incelenmiştir. Araştırmanın çalı̧̧ma grubu, Kuzey Kıbrıs Türk Cumhuriyeti’nde (KKTC) öğrenim gören 268 üniversite öğrencisinden oluşmaktadır. Araştırmaya katılanların yaş ortalaması 21.07, yaşları 18 ile 29 arasında değişmektedir, bu katılımcıların 156 (\% 58) kadın, 112 (\% 42) erkektir. Araştırmada veri toplamak amacıyla Yaşamda Anlam Ölçeği (YAÖ) ve Psikolojik İyi-Oluş Ölçeklerinden Yaşam Amacı Ölçeği (P-YAÖ) kullanılmıştır. Veriler SPSS 20 programı kullanılarak test edilmiştir. Cinsiyetin yaşamda anlam ve yaşam amacı üzerindeki etkisini test etmek amacıyla tek yönlü MANOVA analizi kullanılmıştır. Yaşamda anlam ile yaşam amacı arasındaki ilişkiyi incelemek için Pearson Korelasyon Katsayısı kullanılmıştır. Araştırma sonucunda, üniversite öğrencilerinin yaşamda anlam düzeyleri ile yaşam amaçları arasında pozitif yönlü ilişki olduğu, yaşamda anlam arayış düzeyleri ile yaşamın amaçları düzeyi arasında negatif ilişki olduğu saptanmıştır. Ayrıca, kadınların yaşamda anlam ve yaşam amacı puanlarının erkeklerden daha yüksek olduğu bulgulanmıştır. Araştırma bulguları ve sınırlılıkları tartışılmış bu bağlamda araştırmacı ve psikolojik danışmanlara yönelik öneriler sunulmuştur.

Anahtar sözcükler: Yaşamda Anlam, Anlam Arayışı, Yaşam Amacı, Üniversite Öğrencileri

\begin{abstract}
The aim of this research was to test the relationship between meaning in life and purpose in life for university students.- In addition to the gender effect on the meaning in life, the search for meaning and purpose in life is investigated. The sample for this study comprised 268 university students in the Turkish Republic of Northern Cyprus. The ages of the participants ranged between 18 and 29 with a mean of 21.07, with 156 (\% 58) women and 112 (\% 42) men forming the genders of these participants. In order to gather the data the Meaning in Life Questionnaire (MLQ) and the Purpose in Life (PL), Measures of Psychological Well-Being were used. The data were analyzed through using SPSS 20. The Pearson Correlation Coefficients were used in order to examine the relationship between meaning in life and purpose in life. One-way multivariate analysis of variance (MANOVA) was conducted in order to test the gender effect on the meaning in life and the purpose in life. The results revealed that there was a positive relationship between the meaning in life levels and the purpose in life levels, and a negative relationship between search levels of purpose in life levels of university students. Also, the research found that the meaning in life and the purpose in life scores of women were higher than for men. The results and limitations of the study are discussed and the recommendations made have been provided to psychological counsellors and researchers.
\end{abstract}

Keywords: Meaning in Life, Search for Meaning, Purpose in Life, University Students

\footnotetext{
* Dr., Yakın Doğu Üniv., Atatürk Eğitim Fak., Rehberlik ve Psikolojik Danış. Böl., Lefkoşa. demirbas.nur@gmail.com
} 
Felsefe yazınında yıllardır sorgulanan yaşamın anlamı günümüz dünyasında psikolojinin de konusu olmuştur. Psikoloji yaşamın anlamından ziyade kişinin yaşamındaki anlam düzeyini, yaşamdaki anlam kaynaklarını ve yaşamın amacını irdelemeye odaklanmıştır. 21. yüzyıl tüm bilim alanlarında olduğu gibi psikolojide de bilimsel çalışmaların önceki bilgi dayanaklarına göre geliştiği bir süreçtir. Bu aşamada pozitif psikolojiye ilgi artmış, kişinin yaşamdaki anlamına vurgu yapan çalışmalar ivme kazanmıştır. Kişinin yaşamda bir anlamının olmasını kişiyi yaşama bağlayan temel bir motivasyon olarak değerlendirmektedir ve II. Dünya Savaşı'nda toplama kamplarında hayatta kalmayı başarabilmiş kişilerin en belirgin özelliği, yaşamlarında bir anlama sahip olmalarıdır (Frankl 2009). Yaşamda anlam ya da yaşamda anlamın varlı̆̆ı, Steger (2009) tarafından kişinin yaşamını anlamlandırmasını sağlayan bir hedefe, bir misyona ya da kapsayıcı bir yaşam amacına sahip olma derecesi olarak tanımlanmıştır. Varoluşçu yaklaşıma göre yaşamda anlam, bireylerin yaşamlarını anlamlı kılan ve yaşamlarında anlam yaratmalarına sebep olan temel motivasyondur ve bireylerin yaşamlarının sınırlı olduğu bilgisiyle yüzleşmeleri sonucu ortaya çıkar (Corey 2005). Buradan hareketle yakınlarını kaybederek ya da ölümden dönerek ölümle yüzleşen insanların, yaşamlarında anlam yaratma eğiliminde oldukları düşünülebilir (Yalom 2001). Bir başka tanımda yaşamda anlam, farklı bir bakış açısıyla olumlu bir kişilik özelliği olarak değerlendirilmektedir (Ryff 1989).

Kişinin yaşamında anlam olmaması "anlamsızlık" olarak adlandırılmıştır (Frankl 2009). Anlamsızlık, kişilerin kendilerini hedefsiz, plansız hissetmeleri ve ne yöne gideceklerini bilmeme durumudur (Harlow \& Newcomb 1990). Anlamsızlık, varoluşçu yaklaşımın dört temel öğesinden biridir. Varoluş̧̧u yaklaşıma göre anlamsızlık, varoluşsal boşluk ya da varoluşsal nevroza neden olur (Yalom, 2001). Varoluşsal boşluk, kişinin can sıkıntısı, duygusuzluk, duyarsızlık yaşaması ne yapacağını bilememesi yaptıklarının amacını sorgulamasıdır. Anlamsızlık, ruh sağlığ ile negatif yönde ilişkilendirilmiştir (Battista \& Almond 1973; Zika \& Chamberlain 1992; Frankl 2009). İnsanlar yaşamlarında anlam eksikliği deneyimlediklerinde yüksek düzeyde sıkıntı (Harlow, Newcomb \& Bentler 1986) yaşamaktadırlar ve sağlıkları olumsuz yönde (Ishida \& Okada 2006) etkilenmektedir. Yaşamda anlamın varlığı ise ruh sağlığı ile pozitif yönde ilişkilidir. Bu konuda yapılan çalışmalar yaşamda anlamın; mutluluk (Chamberlain \& Zika 1988; Steger, Oishi \& Kesebir 2011), iyi-oluş (Bonebright, Clay \& Ankenmann 2000) ve sosyal yakınlık (Ryff 1989) gibi olumlu psikoloji bileşenleri ile pozitif yönde ilişkili olduğunu ortaya koymuştur.

Yaşamda anlam konusunda üzerinde durulan diğer kavram yaşamda anlam arayışıdır. Frankl (2009), yaşamda anlam arayışının ruh sağlığına olumlu etkisinin olabileceğini ileri sürmüştür. Klinger (1998) ise, anlam arayışının ruhsal problemlerin belirtisi olabileceğini söylemektedir. Yaşamda anlam arayışı, anksiyete (Steger et al. 2006) ve sosyal yalıtım (Steger et al. 2008) gibi olumsuz kavramlar ile ilişkilendirilmiştir. Steger ve diğ. (2006) yaşamda anlam kavramının yaşamda anlamın varlı̆̆ 1 ve yaşamda anlam arayışının birleşkesi olduğunu ileri sürmüşlerdir. Ancak sözü edilen araştırmacılar varlık ve arayış olarak adlandırılan bu iki kavramın arasında ilişki olmadığını belirtmektedirler. Bu paradoks şu şekilde detaylandırmıştır: bir kişi yaşamda anlam arayışı içindeyken aynı zamanda yaşamda anlama sahip olabilir ya da bir kişi yaşamında zaten bir anlama sahip olduğu için anlam arayışı içinde olmayabilir. Yaşamında bir anlama sahip iken anlam arayışı içindeki kişilere Gandi, Malcom X gibi kişiler örnek gösterilebilir. Bu paradoksal durumun nedeni yaşamda birden çok anlam kaynağının olmasından ileri gelmektedir. Örneğin, yaşamının anlamı maratonda birinci olmak olan biri bu sonucu elde ettiğinde yaşamını anlamlı hale getirecek başka bir anlam arayışı içine girebilir. Ancak bu durum için mutlaka yaşamında anlamsızlığ deneyimlemesi gerekli değildir. Yaşamda anlam arayışı, yolculuk; yaşamda anlamın varlığı varış noktası somutlaştırılabilmektedir (Steger 
et al. 2006). Diğer taraftan yaşamın bir amacı olmadan anlamlı bir yaşamın olmayacağını ileri sürülmüştür (Battista \& Almond 1973).

Amaçlar, psikolojik iyi oluş bakış açısının merkezinde yer alan anlam, hedef ve yaşam görevlerini yansıtmaktadır (Ryan \& Deci 2001). Yaşam amacı, kişinin hedeflerine ulaşmak için mücadele etmesi ve varoluşsal nevroza karşı anlam yaratması olarak tanımlanmıştır (Steger et al. 2008). Ryff'a (1989) göre amaçlar, psikolojik iyi oluş bakış açısının merkezinde yeralan anlam, hedef ve yaşam görevlerini yansıtmaktadır. Yaşam amacına sahip olmak öznel iyi oluşu (Emmons 2005; Judge et al. 2005; Cotton-Bronk et al. 2009) ve yaşam doyumu düzeylerini artırmaktadır.

Yaşamın birçok yönünü kapsayan yaşam amaçları, Türk eğitim sisteminde genellikle geleceğe ilişkin bir hedefe özellikle de kariyer kapsamında ele alınmaktadır. Nitekim Türkiye'de üniversite öğrencileri üzerinde gerçekleştirilen bir çalışmada, öğrencilerin en çok önemsedikleri amaç, özel yetenek ve eğilimlerini kullanmaktır, gelecek beklentileri ise, "mesleğe hazırlanma" olarak belirlenmiştir (Şahin, Zoraloğlu \& Şahin-Fırat 2011). Eğitimin amacının bir mesleğe insan gücü hazırlamak oluşu ve ekonomik nedenler ile sınırlanıyor oluşu yaşam amaçları konusunda öğrencilere sınırlı bir bakış açısı sunmaktadır. Oysa mutluluğun somut belirleyicilerinden biri olan yaşam amaçlarının her yönünün ayrıntılı irdelenmesi mutlu nesillerin yetişmesi için son derece önemlidir. Üniversite öğrencilerinin gelişimsel dönemleri dikkate alındığında, çoğu ilk kez ailelerinden ayrılmış ve öğrenimlerinin gereği karşılaştıkları birçok güçlükle baş etmek zorundadırlar. Bu nedenle üniversite öğrencilerinin içinde bulundukları dönem yaşamda anlam ile yakından ilgilidir (Demirbaş 2010). Deneysel ve teorik yazın, amaç anlayışının genç insanların yaşamında pozitif bir rol oynadığını öne sürmektedir (Bronk 2006). Yine benzer şekilde amaçlar, psikolojik iyi oluş bakış açısının merkezinde yer alan anlam, hedef ve yaşam görevlerini yansıtmaktadır (Ryan \& Deci 2001).

Yaşamda anlam ve yaşam amacı Türkiye'de son on yıldır incelenmeye başlamıştır. Bu nedenle yaşamda anlam ve yaşam amacının ilişkili olduğu değişkenler ile yapılan çalışmaların sayısı Türkiye'de oldukça azdır. Yaşam amaçları ile öznel iyi-oluş ilişkisini inceleyen çalışmalarda (İlhan \& Özbay 2010; Şahin et al. 2012) yaşamda anlamın öznel iyi-oluşu yordadığı belirlenmiştir. Bir başka çalışmada yaşamda anlam ile ego-sağlamlığı arasında pozitif yönde ilişki bulgulanmıştır (Demirbaş \& Keklik 2011). Bir model test etme çalışmasında ise, kişilik ve yaşamda anlam ilişkisinde temel psikolojik ihtiyaçların aracı rolü vurgulanmıştır (Demirbaş 2014).

Yaşamda anlam ve yaşam amacı iki ayrılmaz yapı olup olumlu psikoloji içinde ele alınmaktadır (Seligman \& Csikszentmihalyi 2000). Ancak yaşamda anlam ve yaşam amacı üzerine çalışan teorisyenler bu konuda görüş birliği içerisinde değildir. Steger (2009) yaşamda anlamın yaşam amaçları ile ilişkili olduğunu, ancak yaşamda anlamın yaşam amacından daha kapsamlı bir noktaya işaret ettiğini savunmaktadır. O'na göre yaşamda anlam, anlam arayışını da kapsamaktadır. Yaşam amacı ise, bir noktaya yönelmiş olmayı ve niyeti ifade etmektedir (Ryff 1989). Örneğin, bir öğrencinin derslerinde başarılı olmak, bir işe girmek gibi yaşam amaçları olabilir; ancak yaşamdaki anlamı derslerinde başarılı olmak değildir. Yaşamda anlam, anlam arayışını da içinde barındıran daha kapsamlı bir yapıdır (Steger et al. 2006). Nitekim Frankl (2009) yaşamda anlam arayışını, yaşamda anlamın oluşturulmasında önemli bir nokta olduğunu savunmaktadır. Bundick (2011) üniversite öğrencilerinde yaşam amaçları hakkında tartışmanın ve yaşam amaçları üzerinde düşünmenin yaşamda anlamın varlığına nasıl bir katkı sağladığını araştırmıştır. İlgili araştırmanın sonunda yaşam amacı hakkında üzerinde düşünmenin yaşamda anlamın varlığıyla orta düzeyde ilişkili olduğunu bulmuştur. Türkiye'de bu iki 
kavram arasındaki ilişkiyi irdeleyen çalışmaya rastlanmamıştır. Tüm bunlardan hareketle, bu araştırmanın amacı üniversite öğrencilerinin yaşam amacı ile yaşamda anlam, yaşamda anlam arayışı ilişkisini ortaya koymaktır. Bu bağlamda aşağıdaki araştırma sorularına yanıt aranmıştır.

- Üniversite öğrencilerinin cinsiyete göre, yaşamda anlam, yaşamda anlam arayış1 ve yaşama amacı farklılaşmakta mıdır?

- Üniversite öğrencilerinin yaşamda anlam, yaşamda anlam arayışı ile yaşam amacı arasında ilişki var mıdır?

\section{Yöntem}

\section{Araştırmanın Modeli}

$\mathrm{Bu}$ çalışma, tarama modellerinden ilişkisel tarama yöntemi ile gerçekleştirilmiştir. İlişkisel tarama, iki ya da daha fazla değişken arasındaki ilişkileri belirlemek amacıyla kullanılmaktadır (Büyüköztürk 2010).

\section{Çalışma Grubu}

$\mathrm{Bu}$ araştırmanın çalışma grubu, KKTC'de öğrenim gören, 268 üniversite öğrencisinden oluşmaktadır. Bu öğrencilerin 156'sı kadın (\% 52), 112'si (\% 48) erkek öğrencidir. Katılımcılar Eğitim Fakültesi, Fen-Edebiyat Fakültesi, Mühendislik Fakültesi ile İktisadi ve İdari Bilimler Fakültesinde öğrenim görmektedirler. Katılımcıların yaş ortalaması $21.07(\mathrm{SS}=2.71)$ ve yaşları 18 ile 29 arasında değişmektedir.

\section{Veri Toplama Araçları}

$\mathrm{Bu}$ araştırmada cinsiyet ve yaş değişkenine ilişkin soruları içeren kişisel bilgi formunun yanı sıra aşağıda açıklanan ölçekler kullanılmıştır. Bu ölçekler, Yaşamda Anlam Ölçeği (YAÖ) ve Psikolojik İyi Oluş Ölçeklerinden biri olan Yaşam Amacı Ölçeği (P-YAÖ) kullanılmıştır.

\section{Yaşamda Anlam Ölçeği (YAÖ)}

YAÖ, yaşamda anlamın varlığı ve yaşamda anlam arayışını ölçmek için her biri 5 maddeden oluşan 10 maddelik bir ölçektir (Steger et al. 2006) Ölçeğin maddeleri 1'den (Kesinlikle doğru değil) 7'ye (Kesinlikle doğru) doğru likert tipi olarak derecelendirilmektedir. Ölçeğin yaşamda anlamın varlığı ve yaşamda anlam arayışı olmak üzere iki alt ölçeği bulunmaktadır. YAÖ'nin Türk kültürüne uyarlama çalışması Demirbaş Çelik ve İşmen Gazioğlu (2015) tarafından yapılmıştır. Varlık boyutunun Cronbach's Alpha katsayısı .88, arayış alt boyutunun Cronbach's Alpha katsayısı .93 olarak bulunmuştur. Bu araştırma için varlık ve arayış boyutları için Cronbach's Alpha katsayısı sırasıyla .79 ve .70 olarak hesaplanmıştır.

\section{Yaşam Amacı Ölçeği (P-YAÖ)}

Yaşam Amacı Ölçeği, Ryff (1989) tarafindan geliştirilen Psikolojik İyi Oluş Ölçekleri'nden biridir. P-YAÖ, 14 maddeden oluşmakta ve 1'den (Hiç katılmıyorum) 6'ya (Tamamen katıllyorum) doğru likert tipi olarak derecelendirilmektedir. Bu ölçek Türk kültürüne Cenkseven ve Akbaş (2007) tarafindan uyarlanmıştır. Bu uyarlama çalışmasına göre ölçeğin Cronbach's Alpha katsayılarının .74 ile .83 arasında olduğu belirlenmiştir. Bu araştırmada P-YAÖ'nin Cronbach's Alpha katsayısı .71 olarak bulgulanmıştır. 


\section{Verilerin Analizi}

Araştırmada elde edilen veriler SPSS 20 programı kullanılarak analiz edilmiştir. Normallik varsayımı Kolmogorov-Smirnov testiyle incelenmiştir. Kolmogorov-Smirnov Testi sonucunda varlık $\mathrm{p}=.14$, arayış $\mathrm{p}=.10$, amaç $\mathrm{p}=.09$ olarak hesaplanmıştır. Kolmogorov-Smirnov normallik testi analiz sonuçları, bağımlı değişkenlerin normal dağılım gösterdiğini kanıtlamaktadır ( $\mathrm{p}>0.05)$. Bu nedenle araştırmanın verileri Çok Yönlü Varyans Analizi (MANOVA) ve Pearson Momentler Korelasyon Katsayısı ile kullanılarak çözümlenmiştir. Araştırmanın bağımsız değişkeni olan öğrencilerin cinsiyetinin bağımlı değişkenler olan yaşamda anlamın varlığı ile arayışı ve yaşam amacı üzerinde anlamlı farklılık oluşturup oluşturmadığ tek yönlü MANOVA ile test edilmiştir. Cinsiyete göre Homojenlik varsayımınının karşılandığ gruplar için Tukey Testi, homejenlik varsayımının karşılamadığı için durumlar için Tamhane's T2 testi yapılmıştır. Araştırmanın bağımlı değişkenleri arasındaki ilişkiyi belirlemek için Pearson Momentler Korelâsyon Katsayısı kullanılmıştır. Tüm veriler, $\mathrm{p}<.05$ düzeyinde değerlendirilmiştir.

\section{Bulgular}

Araştırmanın bağımlı değişkenleri olan yaşamda anlamın varlığı (Varlık), anlam arayışı (Arayış) ve yaşam amacina (Amaç) ilişkin standart sapma (SS) ve ortalama (X) değerleri Tablo 1 'de sunulmuştur.

Tablo 1. Bağımlı Değişkenlerin Standart Sapma ve Ortalama Değerleri

\begin{tabular}{|c|c|c|c|}
\hline & Varlık & Arayış & Amaç \\
\hline Standart Sapma & 6.39 & 8.21 & 9.59 \\
\hline Ortalama & 26.5 & 22.3 & 57.6 \\
\hline
\end{tabular}

Araştırmanın bağımlı değişkeni olan cinsiyetin yaşamda anlamın varlığı, anlam arayışı ve yaşam amacı üzerinde etkisine ilişkin MANOVA sonuçları Tablo 2'da gösterilmiştir.

Tablo 1. Cinsiyete İliş̧kin MANOVA Sonuçları

\begin{tabular}{|c|c|c|c|c|c|}
\hline \multirow{2}{*}{ Kaynak } & Bağımlı Değişkenler & df & $\mathbf{F}$ & $\mathbf{p}$ & $\mathbf{\eta}$ \\
\hline \multirow{3}{*}{ Cinsiyet } & Varlık & 1 & 15.9 & .000 & .238 \\
\cline { 2 - 6 } & Arayış & 1 & .815 & .367 & .005 \\
\cline { 2 - 6 } & Amaç & 1 & 8.47 & .004 & .017 \\
\hline
\end{tabular}

Tablo 2 incelediğinde cinsiyete göre yaşamda anlam arayışı $[F(1,267)=.82, p=.36, \eta=.00]$ anlamlı farklılık göstermemektedir. Ancak etki büyüklüğü oldukça düşüktür. Cinsiyete göre yaşamda anlamın varlığ $[F(1,267)=20, p=.00, \eta=.23]$ ve yaşam amacı $[F(1,267)=8.5, p$ $=.004, \eta=.01$ anlamlı farklılık göstermektedir. Buna göre, kadınların yaşamda anlamın varlığ puanları $(27.8>24.7)$ ve yaşam amacı puanları $(59>55.6)$ erkeklerden daha yüksek bulunmuştur.

Öğrencilerin yaşamda anlamın varlığı, anlam arayışı ve yaşam amacı düzeyleri arasındaki ilişkiler Pearson Korelasyon Katsayısı ile hesaplanmıştır. Bu ilişkilere yönelik sonuçlar Tablo 3 'te yer almaktadır. 
Tablo 2. Bağımlı Değişkenler Arasındaki Pearson Korelasyon Testi Sonuçları

\begin{tabular}{|c|c|c|c|}
\hline Bağımlı Değişkenler & Varlık & Arayış & Amaç \\
\hline Varlık & 1 & & \\
\hline Arayış & -.33 & 1 & \\
\hline Amaç & $.432^{* *}$ & $-.121^{*}$ & 1 \\
\hline$* * \mathrm{p}<.01, * \mathrm{p}<.05$ & & & \\
\hline
\end{tabular}

Tablo 3'e göre, yaşamda anlamın varlı̆̆ 1 ile yaşamda anlam arayışı arasında anlamlı bir ilişki yoktur. Yaşamda anlamın varlığ 1 yaşam amacı ile pozitif yönde orta düzeyde $(\mathrm{p}=.43)$ ilişkili bulunmaktadir.

\section{Tartışma, Sonuç ve Öneriler}

$\mathrm{Bu}$ araştırmada, üniversite öğrencilerinin cinsiyete göre yaşamdaki anlamlarının, anlam arayışlarının ve yaşam amaçlarının farklılaşıp farklılaşmadığı incelenmiştir. Araştırma bulguları, yaşamda anlamın varlığı ve yaşam amacının cinsiyete göre farklılaştığını, yaşamda anlam arayışının ise farklılaşmadığını göstermiştir. Buna göre kadınların yaşamda anlamın varlığ 1 ve yaşam amacı düzeyleri erkeklerden daha yüksektir. Yapılan çalışmalar üniversite öğrencilerinin yaşamda anlamın varlığı ve yaşamda anlam arayışı düzeylerinin cinsiyete göre değişmediğini ortaya koymuştur (Steger et al. 2006; Demirbaş 2010). Bu araştırmada yaşamda anlam arayış1nın cinsiyete göre farklılaşmadığının bulgulanması sözü edilen araştırma sonuçları ile örtüşmektedir. Ancak yaşamda anlamın varlığının cinsiyete göre farklılaşması aradan geçen yıllarla birlikte kadın ve erkeklerin yaşamda anlam düzeyinde değişiklik olduğunu göstermektedir. Diğer taraftan yaşam amacı ile ilgili çalışmada (İlhan \& Özbay 2010) kızların içsel amaç ve bazı dışsal amaç türlerinde puanları daha yüksek düzeydir. Bu araştırma sonucunun da gösterdiği üzere yaşam amacı kadın grubunda daha yüksek düzeydedir.

$\mathrm{Bu}$ araştırma sonucuna göre, yaşamda anlamın varlığı ile yaşam amacı arasında pozitif yönlü ilişki belirlenmiştir. Buna göre üniversite öğrencilerinin yaşam amacı arttıkça yaşamda anlam düzeyleri de artmaktadır. Bazı teorisyenler (Ryan \& Deci 2000; Seligman \& Csikszentmihalyi 2000) yaşam amacı ile yaşamda anlamın birbirinin yerine kullanılabileceğini ifade etmektedirler. Ancak Steger (2009) yaşamda anlamın tanımı anlamın amaçtan daha kapsayıc1 olduğu ve amaçtan daha üst düzey bir yapıya işaret ettiğini ileri sürmektedir. Yaşamda anlam ve yaşam amacına ilişkin araştırma yaparken hangi ölçme aracının kullanıldığı önemli bir belirleyicidir. Yaşamda anlam ve yaşam amacı teorisyenlerinin bir kısmı yaşam amacı ve yaşamdaki anlamı keskin çizgilerle ayırmaktadır. Nitekim bu çalışma Steger ve diğerlerinin (2006) ölçme aracıyla gerçekleşmiştir. Emmons'a (2003) göre, yaşam amaçlarına sahip olmak bireylerin yaşamlarını anlamlandırmalarını kolaylaştırmaktadır. Bundick (2011) üniversite öğrencileri ile yaptığı çalışmada yaşam amacı ile yaşamda anlamın varlığ koymuştur. Sözü edilen çalışmada gençlerin yaşam amaçları hakkındaki derinlemesine tartışmanın gençlerin yaşamlarındaki anlam düzeyini artırdığın belirlenmiştir. Bu araştırmada aynı ilişkiyi doğrulamaktadır.

$\mathrm{Bu}$ araştırmada yaşam amaçları, kişinin yaşamındaki duygusal bütünleşmeyi ve kişinin yaşamda bir hedefe, bir amaca yönelmesini ifade etmektedir (Ryff 1989). Ancak bu amaçlarının neler olduğu somut olarak ortaya konulmamıştır. Örneğin, Kasser ve Ryan (1996) yaşam amaçlarını içsel ve dışsal amaçlar olarak ikiye ayırmaktadırlar. Yaşam amaçları ilgili yapılan bir araştırmada (Macdonald, Wong \& Gingras 1998) yaşam amaçlarının öz-aşkınlık, yakınlık, ilişki, din, başarı, adalet ve kendini kabul olmak üzere yedi kategoriden oluştuğu ifade 
edilmektedir. Bundick (2011) ise yaşam amaçları ile ilişkili somut anlamlı etkinliklerden söz etmektedir. Ancak bu araştırmada üniversite öğrencilerinin amaçlarının neler olabileceğine dair bilgiler yer almamıştır. $\mathrm{Bu}$ araştırmanın önemli sınırlılıklarından biridir. Bu araştırma sonucunda yaşam amacı ve yaşama anlam ilişkisinin orta düzeyde olmasının sebebi yaşam amaçlarıyla ilgili maddelerin doğrudan sorulması yerine genel amaç ifadelerinden söz edilmiş olmasından kaynaklanabilir. Şöyle ki her iki ölçekte genel bir anlam ve amaç ifadesine gönderme yapmaktadır ancak anlamın ya da amacın neler olabileceğine dair somut ifadelere yer vermemektedir. Bundan sonra yapılacak çalışmalarda yaşamda anlamın kaynaklarına ya da amaçlarla ilişkili anlamlı etkinlikler hakkında bilgiler sunan ölçme araçlarının kullanılması amaç-anlam ilişkisi hakkında daha detaylı sonuçlara ulaşılmasını sağlayabilir.

$\mathrm{Bu}$ araştırma sonucuna göre, yaşam amacı ile yaşamda anlam arayışı arasında negatif yönlü düşük düzeyde ilişki bulunmuştur. Buna göre, üniversite öğrencilerinin yaşam amacı düzeyleri arttıkça yaşamdaki anlam arayış düzeyleri azalmaktadır. Ancak bu ilişkinin düzeyi düşüktür. Steger ve diğ. (2006) yaşamda anlam arayışını açıklarken kişinin daha önceki anlam düzeyine bakılması gerektiğini vurgulamaktadırlar. Öyle ki, bir kişi, yaşamında halihazırda bir anlama sahipken anlam arayabilir. Tam tersi olarak kişi yaşamında hiçbir anlamı yokken de anlam arayışı içerisinde olabilir. Yaşamda anlam araştırmaları anlam arayışının sağlıklı ya da sağlıksız olmasının ölçütü olarak altında yatan motivasyonunun bilinmesi gerekliliğini işaret etmektedir (Steger et al. 2010). Tüm bunlardan dolayı yaşam amacı ile yaşamdaki anlam ilişkisini irdelerken var olan anlam düzeyinin kümeleme analizi gibi yönetmelerle incelenmesi bu noktada detaylı sonuçlar için yol gösterici olabileceği düşünülmektedir. Üniversite öğrencilerinin yaşam amaçlarının olmasının yaşamlarındaki anlam anlayışını artmasına katkı sağladığı söylenebilir. Bunun için de üniversite öğrencilerinin yaşam amaçlarını geliştirmelerine yönelik grupla psikolojik danışma oturumlarının düzenlenmesi onların yaşamlarındaki anlamlarının artırmaları için yol gösterici olabileceği düşünülmektedir.

$\mathrm{Bu}$ araştırma yaşamda anlam ve yaşam amaçları ilişkisini genel hatlarıyla ortaya koymuştur. $\mathrm{Bu}$ araştırmanın sınırlılıklarından en önemlisi üniversite yaşam amaçlarının neler olduğunun somut olarak belirlenmemiş olmasıdır. Bir diğer sınırlılık ise, yaşam amacı ve yaşamda anlam ile ilişkili temel kavramlardan biri olan iyi-oluşun araştırmaya dahil edilmemiş olmasıdır. Ayrıca araştırmanın yalnızca üniversite öğrencileri ile gerçekleştirilmiş olması da araştırmanın genellenebilirliğini sınırlamaktadır. Bundan sonra yapılacak araştırmalarda yaşam amaçlarının somut yapısını ortaya koyan ölçme araçları kullanılarak yaşamda anlamı açıklayıcı daha detaylı bilgilere ulaşılabilir. Yaşam amaçlarıyla ilgili görüşme yapılarak üniversite öğrencilerin yaşam amaçlarının neler olduğu belirlenebilir. Yaşamda anlamın kaynakları konusunda derinlemesine nitel çalışmalar yürütülebilir. Yaşam amacı ile yaşamdaki amaç ilişkisi ergen grubunda irdelenebilir. Bu bağlamda farklı yaş gurupları için karşılaştırılmalı sonuçlar sunulabilir. Yaşam amacı, yaşamda amaç ilişkisine öznel iyi oluş dahil edilerek yapısal modeller test edilebilir. 


\section{KAYNAKÇA}

Battista J. \& Almond R. (1973). “The Development of Meaning in Life”. Psychiatry 36 (1973) 409-427. Doi: $10.1177 / 0040571 X 7908200403$.

Bonebright C. A., Clay D. L. \& Ankenmann R. D. (2000). "The Relationship of Workaholism with workLife Conflict, Life Satisfaction, and Purpose in Life”. Journal of Counseling Psychology 47/4 (2000) 469-477. Doi: 10.1037/0022-0167.47.4.469.

Bronk K. C. (2006). Portraits of Purpose: A Study Examining the Ways a Sense of Purpose Contributes to Positive Youth Development. (Unpublished Doctoral Dissertation). Stanford University, Stanford, CA 2006.

Bundick M. J. (2011). "The Benefits of Reflecting on and Discussing Purpose in Life in Emerging Adulthood”. New Directions for Youth Development 132 (2011) 89-103. Doi: 10.1002/yd.430

Büyüköztürk Ş. $\left(2010^{11}\right)$. Sosyal Bilimler Iç̧in Veri Analizi El Kitabı. Ankara 2010.

Cenkseven F. \& Akbaş T. (2007). “Üniversite Öğrencilerinde Öznel ve Psikolojik İyi Olmanın Yordayıcılarının İncelenmesi”. Türk Psikolojik Danışma ve Rehberlik Dergisi 3/27 (2007) 43-65.

Chamberlain K. \& Zika S. (1988). "Measuring Meaning in Life: An Examination of Three Scales”. Personality and Individual Differences 9/3 (1988) 589-596. Doi: 10.1016/0191-8869(88)90157-2

Corey G. (2005). Psikolojik Danışma, Psikoterapi Kuram ve Uygulamaları. Çev. Tuncay Ergene. Ankara 2005.

Cotton-Bronk K., Hill P. L., Lapsley D. K., Talib T. L. \& Finch H. (2009). "Purpose, Hope, and Life Satisfaction in Three Age Groups". The Journal of Positive Psychology 4/6 (2009) 500-510. Doi: 10.1080/17439760903271439.

Demirbaş N. (2010). Yaşamda Anlam ve Yllmazlık. Yayımlanmamış Yüksek Lisans Tezi. Hacettepe Üniversitesi, Ankara 2010.

Demirbaş N. (2014). Üst-Düzey Kişilik ve Yaşamda Anlam: Temel Psikolojik İhtiyaçların Rolünün Yapısal Eşitlik Modellemesi İle İncelenmesi. Yayımlanmamış Doktora Tezi. İstanbul Üniversitesi, İstanbul.

Demirbaş N. \& Keklik İ. (2011). "Üniversite Öğrencilerinin Yaşamda Anlam ve Yılmazlıkları Arasındaki İlişki”. XI. Ulusal Psikolojik Danışma ve Rehberlik Kongresi (3-5 Ekim 2011). (2011) 3-5.

Demirbaş-Çelik N. \& İşmen-Gazioğlu E. (2015). "Yaşamda Anlam Ölçeği Lise Formu: Türkçe Geçerlik ve Güvenirliği”. Mehmet Akif Ersoy Üniversitesi Ĕgitim Fakültesi Dergisi 33 (2015) 42-60.

Emmons R. A. (2003). "Personal Goals, Life Meaning, and Virtue: Wellsprings of a Positive Life. Flourishing: Positive Psychology and the Life Well-Lived”. American Psychological Association XX (2003) 105-128. Doi: 10.1037/10594-005.

Emmons R. A. (2005). “Striving for the Sacred: Personal Goals, Life Meaning, and Religion”. Journal of Social Issues 61/4 (2005) 731-745. Doi: 10.1111/j.1540-4560.2005.00429.x.

Eryılmaz A. (2012). "Pozitif Psikoterapi Bağlamında Yaşam Amaçları Belirleme Ölçeğinin Üniversite Öğrencileri Üzerinde Psikometrik Özelliklerinin İncelenmesi”. Kilinik Psikiyatri 15 (2012) 166-174.

Frankl V. E. (20094). Insanın Anlam Arayışı. Çev. Selçuk Budak. İstanbul 2009.

Harlow L. L. \& Newcomb M. D. (1990). “Towards a General Hierarchical Model of Meaning and Satisfaction in Life”. Multivariate Behavioral Research 25/3 (1990) 387-405. Doi: 10.1207/s153279 06mbr2503 9.

Harlow L. L., Newcomb M. D. \& Bentler P. M. (1986). “Depression, Self-Derogation, Substance Use, and Suicide Ideation: Lack of Purpose in Life as a Mediational Factor”. Journal of Clinical Psychology 42/1 (1986) 5-21. Doi: 10.1002/1097-4679(198601)42:1<5::AID-JCLP2270420102>3.0. CO;2-9

İlhan T. \& Özbay Y. (2010). "Yaşam Amaçlarının ve Psikolojik İhtiyaç Doyumunun Öznel İyi Oluş Üzerindeki Yordayıcı Rolü”. Türk Psikolojik Danışma ve Rehberlik Dergisi 4/34 (2010) 109-118.

Ishida R. \& Okada M. (2006). "Effects of a Firm Purpose in Life on Anxiety and Sympathetic Nervous Activity Caused by Emotional Stress: Assessment by Psycho-Physiological Method”. Stress and Health 22 (2006) 275-281. Doi: 10.1002/smi.1095 
Judge T. A, Bono J. E., Erez A. \& Locke E. A. (2005). "Core Self-Evaluations and Job and Life Satisfaction: the Role of Self-Concordance and Goal Attainment". The Journal of Applied Psychology 90/2 (2005) 257-68. Doi: 10.1037/0021-9010.90.2.257

Kasser T. \& Ryan R. M. (1996). "Further Examining the American Dream: Differential Correlates of Intrinsic and Extrinsic Goals”. Personality and Social Psychology Bulletin 22/3 280-287. Doi: $10.1177 / 0146167296223006$

Klinger E. (1998). "The Search for Meaning in Evolutionary Perspective and its Clinical Implications". Ed. P. T. P. Wong. The Human Quest for Meaning: A Handbook of Psychological Research and Clinical Applications (1998) 27-50. Erlbaum.

Macdonald M. J., Wong P. T. P. \& Gingras D. T. (1998). "Meaning-in-Life Measures and Development of a Brief Version of the Personal Meaning Profile”. Ed. P. T. P. Wong. The Human Quest for Meaning: A Handbook of Psychological Research and Clinical Applications (1998) 357-382. Erlbaum.

Ryan R. M. \& Deci E. L. (2000). "The Darker and Brighter Sides of Human Existence: Basic Psychological Needs as a Unifying Concept”. Psychological Inquiry 11/4 (2000) 319-338.

Ryan R. M. \& Deci E. L. (2001). "On Happiness and Human Potentials: a Review of Research on Hedonic and Eudaimonic Well-Being”. Annual Review of Psychology 52 (2001) 141-166. Doi:10.1146/annurev.psych.52.1.141

Ryff C. D. (1989). "Happiness is Everything, or is it? Explorations on the Meaning of Psychological Well-Being”. Journal of Personality and Social Psychology 57/6 (1989) 1069-1081. Doi: 10.1037//0 022-3514.57.6.1069

Seligman M. E. P. \& Csikszentmihalyi M. (2000). Positive Psychology: An Introduction. American Psychologist 55/1 (2000) 5-14. Doi:10.1037//0003-066X.55.1.5

Steger M. F. (2009). "Meaning in Life”. Ed. L. Shane \& C. R. Snyder. Oxford Handbook of Positive Psychology (2009) 679-689. Oxford.

Steger M. F., Frazier P., Oishi S. \& Kaler M. (2006). "The Meaning in Life Questionnaire: Assessing the Presence of and Search for Meaning in Life”. Journal of Counseling Psychology 53/1 80-93. Doi: 10.1037/0022-0167.53.1.80

Steger M. F., Kashdan T. B., Sullivan B. A. \& Lorentz D. (2008). "Understanding the Search for Meaning in Life: Personality, Cognitive Style, and the Dynamic Between Seeking and Experiencing Meaning”. Journal of Personality 76/2 (2008) 199-228. Doi: 10.1111/j.1467-6494.2007.00484.x

Steger M. F., Oishi S. \& Kesebir S. (2011). "Is a Life without Meaning Satisfying? The Moderating Role of the Search for Meaning in Satisfaction with Life Judgments". The Journal of Positive Psychology 6/3 (2011) 173-180. Doi: 10.1080/17439760.2011.569171

Şahin M., Aydın B., Sarı S. V., Kaya S. \& Pala H. (2012). “Öznel İyi Oluşu Açıklamada Umut ve Yaşamda Anlamın Rolü”. Kastamonu Eğitim Dergisi 20/3 (2012) 827-836.

Yalom I. D. (2001). Varoluşçu Psikoterapi. Çev. Zeliha İyidoğan Babayiğit. İstanbul 2001.

Şahin İ., Zoraloğlu Y. R. \& Şahin-Fırat N. (2011). "Üniversite Öğrencilerinin Yaşam Amaçları, Eğitsel Hedefleri, Üniversite Öğreniminden Beklentileri ve Memnuniyet Durumları”. Kuram ve Uygulamada Eğitim Yönetimi 17/3 (2011) 429-452.

Zika S. \& Chamberlain K. (1992). "On the Relation Between Meaning in Life and Psychological WellBeing”. British Journal of Psychology 83/1 (1992) 133-145. 